which most of all requires to be removed; except indeed as an occasional resort in dealing with certain patients. Should not our motto be, that there is no occasion for an honest mind to be reserved if he can escape misinterpretation.

Reserve is anything but a positive good; its best characteristic is, that it hides greater evils. Candour, on the other hand, is a positive good, and its worst characteristic is, that it is sometimes unguarded with those who have not the capacity to understand its voice. And yet sad, rather than strange, is it to say, that reserve is looked upon as a sign of power of mind, as a mark of experience and worth, as a thing above all others necessary for the conduct of affairs; so much so, that he who insists upon a contrary line of conduct runs the chance of being esteemed inexperienced and untrustworthy. I say that this is sad rather than strange, for it is only an additional proof of the imperfection and disorder of our present state of being. But at the same time, for few things have we more reason to be thankful than to find that at the present day a dawn of better things is beginning to appear. Men seem inclined to do away with that system which suits children, weakminded persons, and only certain classes of the insane; and to adopt that reality and frankness which men of sound mind should be deemed capable of appreciating, and which many partially insane appreciate keenly. As education advances, and minds become more comprehensive, men seem inclined to judge rather by observing minute indices of truth than by plausible appearances and artificial airs of superiority; so much so, that we now-a-days can hardly conceive how our fathers could have been on the one hand so easily deceived, or on the other, so presumptuously imposing. In nothing was this state of things more apparent than in the treatment of the insane.

Thus, to the superintendent, to the resident patients, and to the friends of resident patients, a frequent enquiry at, and personal inspection of, private asylums would be disagreeable and injurious, even if it were a sufficient and satisfactory mode to the person wishing to obtain information, (which it cannot be;) therefore it is most desirable not to rely on this too much, however important it may be.

The Conclusion.-Those who feel that such an amount of inspection and publication of internal arrangements as I have advocated in this and a preceding article, would be insupportable, might say, why not insist on public asylums for the upper classes at once, and do away with private asylums altogether? My answer to such an observation would be, that no doubt if the evils of the private system were deemed irremediable, or if their evils exceeded their advantages, this alternative would be had recourse to. But there are many reasons, sufficiently manifest, why this alternative need not be thought of. Among them are the following:-In the first place, the private system, if sufficiently guarded, has its own peculiar advantages, even for the public. The upper classes dislike sending their rela. tions to public institutions of any sort, and there would be some difficulty in making public asylums as private as many might desire. Moreover, a superintendent of a private house would in many cases take a greater interest in rendering his own house like a private home, and would have a greater facility for doing so than in the case of a public asylum. Secondly, a vast amount of capital is vested already in private establishments, which it would be equally unjust and difficult to interfere with carelessly, especially when progressive improvement is being made. Thirdly, why not give the private asylums a fair trial, under a system of sufficient inspection and publicity. The difficulties just alluded to do not obstruct the path of any amount of reform in the private system.

But there is one party which requires to be aroused into action, perhaps more than any other, in the cause of improving asylums; and this consists of the friends of patients. We should have thought that such as these would take the lead in all such matters; but personal considerations keep them back. The public are in earnest in the matter; quondam patients are some of them over-zealous; medical men connected with asylums are stirring in the canse. But this class is led by all, rather than takes the lead; and yet the evidence they can afford, and the interest they must feel in the subject, are most important for its advancement. Their sincere earnestness would be worth much more than the artificial zeal of many demagogues, or the anarchical aspirations of many who have been patients; and their knowledge of the necessities of the case would be a good guide for the sympathizing ardour of the public. The cause requires peculiarly single-minded earnestness to back it, for it is beset by various foes-the stand-still and the hobby-rider, the indifferent and the furious reformer, the conceited man of action, who gains far more applause than he deserves, and the man of good in. tentions, who is not energetic enough; there is a Scylla and Charybdis on either hand, and only the man of experience, sound sense, and humanity, can guide the vessel through the opposing difficulties.

\section{REPORT OF A CASE OF MOLLITIES OSSIUM.} WITH REMARKS.

Bx R. MAsON, Ese, M.R.C.S.E.

MoLLitres ossium may be ranked with those diseases on which modern science has shed but little light; its pathology and treatment are still but little understood; fortunately its occurrence is exceedingly rare, it but seldom being brought under the notice of the surgeon, thus conferring upon it an unusual degree of interest, and which has been the chief inducement for publishing the particulars of a case which came under my observation, some time back, while performing the duties of house-surgeon at St. Bartholomew's Hospital; and as the treatment employed by Mr. Lloyd, under whose care the patient was, materially benefited her condition, the full particulars of the case will prove exceedingly interesting to all those who may have observed or treated this distressing malady.

The subject of these remarks was a well-formed female, thirty years old, of extremely healthy appearance, having light hair and blue eyes; her features were good, and the expression of her countenance exceedingly intelligent. She is stated to have enjoyed good health up to the age of twenty-one, at which time she experienced a fall down a dozen stone steps, hurting the lower part of her back rather severely. At twenty-four, she began to grow weak, and felt very much exhausted after ordinary fatigue of any kind. A short time after this she was treated for rheumatism, and bled, leeched, \&c.; but continuing to get worse, she was advised to go to Bath, and avail herself of the benefit of the waters. She sojourned here for five months, without improvement, her strength becoming more impaired daily. This impairment of strength, however general, was felt most in the right lower extremity, and was accompanied by a pain proceeding downwards from the spine towards the limb; and it was at this period that the first palpable indication of the disease under consideration presented itself, in the limb becoming bent. Soon afterwards, she began to suffer from violent spasms in the same limb, which became now quite incapacitated from its office, either as a member of progression, or support for the weight of her body. She was now compelled, therefore, to lie in bed, taking nourishing diet, and the vinum ferri as medicine.

The next important circumstance that happened in regard to the disease, was in the metacarpal bones of both hands becoming bent, and caused by the force used in grasping the bed-posts while getting in and out of bed. During this period her health generally was good. About this time she first came under observation, and the examination of her limbs gave the following appearances:- The metacarpal bones of either hand would seem to indicate as having been broken in their middle, or of there being a double row of knuckles; the left arm presented, just above the elbow, on the outer side, a hard Iump, giving the idea of callus. This arm was quite useless, she being obliged to support and move it with her other one. On the radius of this same arm there existed another similar lump, as also on the radius of the opposite side. The right thigh presented a largish projection about its middle, or, more intelligibly speaking, the limb appeared bent. Although both lower extremities were equally weak, there existed no such deformity in the left. There was slight lateral curvature of the spine. The treatment pursued consisted in nourishing diet, in the shape of meat and porter, with occasionally fish, and rest in bed, together with the administration of the cod-liver oil, in doses of half an ounce three times a day; and this mode appeared to have a most beneficial effect, for, at the expiration of several months, not only was the general health improved, but also the condition of her limbs. The metacarpal bones of either hand projected much less, and were firmer to the feel. The swellings on either arm were much reduced in size, and the use of the left arm was gained to a great extent.

This case presents, in its outline, the same train of symptoms and phenomena as recorded by those authors who have written on this disease, - the general debility and muscular pains, and phosphatic deposits in the urine, preceding, in this case, as in all those on record, the softening of the bones. There are a great many cases of this peculiar disease related; and what is very remarkable, the subjects of it have been almost without exception females, and in some instances of a very advanced age. Mr. Curling mentions an instance, where the patient had attained the age of serenty-one; and Otto, the celebrated pathologist of 
Breslau, notices a preparation in the anatomical museum at Bonn, the subject of which was nearly eighty. The disease does not appear to be confined to the human species, for it has been observed in quadrupeds, as the lion, ox, \&c.; and Mr. Solly mentions as having heard of its occurrence in dogs; and in all these instances, it has precisely similated, in morbid respects, the softening characteristic of the complaint in man, the bones after death, as in the case of Madame Supiot, (related in Cooper's Practical Surgery, having been easily divided by a common scalpel. The analyzation of the bones, in this disease, has proved the great disproportion of the calcareous and organic substances, the phosphatic elements not being more than one-fifth or oneeighth of the total weight of the bone; as also the almost constant presence of a peculiar red grumous matter, seeming to usurp the place of the phosphate of lime, which is considered by Mr. Solly as an adventitious morbid product, and not, as some have supposed, simply the fatty matter of the bone, altered by the effusion of blood into it.

Various causes have been assigned by different authors for the appearance of this disease; thus cold, sudden fright, excessive grief, misery, and poverty, have been advanced; rheumatism and scurvy have also been supposed by some to have induced its appearance. That in the case under consideration the shock experienced from the fall, mentioned as having occurred shortly before the disease presented itself, may have acted through the medium of the nervous system in producing the symptoms and change in the condition of the osseous system, seems highly probable, and especially so in the absence of any other appreciable cause in an otherwise healthy female. But, however, such is the extreme obscurity in which the disease is involved, that one can only attempt at most to hazard a conjecture concerning it until such times as a new light shall be thrown upon its nature. Hitherto, no successful mode of treatment has been discovered capable of arresting the progress of this complaint, all endeavours at remedial aid having proved abortive. It would seem, as debility is the most striking symptom almost always present, that the most feasible plan would be to improve the constitution by any means calculated to restore the impaired health, and so combat the disposition of the bones to soften and lose their power of support; and certainly in the case of the female recited above, this plan did appear to answer favourably; and although a perfect cure was not effected, the result was exceedingly gratifying, and as far successful as could be anticipated in the treatment of a case of this distressing malady.

Holloway, 1851.

\section{CASE OF PULMONARY ABSCESS. WITH REMARKS.}

By ROBERT MOLLOY, EsQ., M.R.C.S., \&c.

My first visit to Mary S- was on the 22nd of March, 1850. She was a thin, spare woman, of very delicate habit, sixtyeight years of age, and had been the subject of spinal distortion from early childhood, which had materially interfered with her growth. She had been the mother of three children, one of her labours being unusually prolonged and severe, but not instrumental. Her bowels were always irritable, generally in a relaxed condition, so that she was unable to take any other than the mildest aperient; and this susceptibility appeared to be maintained by her occupation, that of a pewopener, exposing her greatly to cold on leaving the heated church after evening service. Five days previously she had received a chill in this manner, and almost immediately after was attacked with severe pain in the side, the continued increase of which induced her friends to summon my attendance. At this time she complained of severe pain in the left side of the chest, but little increased on pressure or in respiration; slight movement only of intercostal muscles, and frequent dry cough. For the relief of these symptoms, mustardpoultices, salines, opiates, and antimonials, with a blister, were had recourse to until the $25 \mathrm{th}$, when the pain and difficulty of breathing having increased, I bled her to twelve ounces, applied another large blister, and gave one grain of calomel and opium ench, with a quarter of a grain of tartarized antimony three times daily. This was continued until the 30 th, when it became necessary to suspend the calomel, in consequence of the gums being slightly affected, and the setting in of mercurial diarrhcea. During this period, three more blisters had been applied, and the same plan of treatment persisted in, but with hardly any relief to the violent thoracic pain, until salivation was effected, when it changed its character to a dull, heavy, throbbing pain, situated in the middle of the left lung posteriorly. The diarrhoea being checked in the course of two or three days, I put her upon three-grain doses of iodide of potassium, with conium, for a reason to be presently stated, together with milk, beef-tea, and half an ounce of wine every two or three hours. This will bring me to the first week in April, when my notes are more circumstantial. The stethoscopic symptoms up to this date were principally pnenmonic crepitation in the middle and base of the left lung; bronchial rhonchi in apex of the same lung, and extending over the whole surface of the right lung; slight dulness on percussion over the base of the left lung, and expectoration of rusty sputa, mixed with much mucus.

A pril 6th.-Face much flushed; recumbent on left side; much pain there at times; tongne coated, dry, and brown; cough troublesome occasionally; expectoration semi-puriform, scanty. - Nine P.M. : Large quantity of pus in sputa; nearly two ounces spat up since six o'clock; cough only occasional; free from pain; breathing less distressed; is quite rational, and inclined to sleep. Compound decoction of sarsaparilla. Continue.

April 7th.-Eight, A.M.: Has passed a very comfortable night, sleeping uninterruptedly five or six hours. Cough occasional expectoration profuse; dirty, dark-looking pus, without smell; tongue still coated and dry, but not quite to the same extent.Eight P.M.: has taken plenty of nourishment; eggs beaten up with wine; and a little chicken was eaten for dinner with relish: Great expectoration, not so dark as in the morning; pain in side less, and breathing not quite so oppressed. To have a pint of bitter ale in divided portions.

8th.-Seems rather better; has passed a comfortable night; cough not very troublesome; expectoration less, globular, approaching more in character to that of chronic bronchitis; tongue still dry and furred.-Seven P.M.: Cough has been very constant since three in the afternoon, with great pain in left side, together with copious, darkish, purulent expectoration; is now much exhausted. Omit ale.

9th.--Passed a tranquil night, and is greatly composed; expectoration still profuse, puriform.-Eight P.M. : Has had but little coughing during the day; expectoration the same, slightly diminished in quantity; pulse strong; tongue moist, though coated inclining to be clean; slept well during the day, and takes. nourishment freely.

10th.- Much the same; the only noticeable change is, that the tongue, though coated and clammy, has lost the dry brown fur; and is cleaning at the edges.

12th.-Had a severe and long-continued fit of coughing during the night, which has induced much depression; tongue more coated, rather hrowner and chippy; pulse, too, more depressed;expectoration less in quantity, but remarkably thick and tenacious. Use opiate liniment to chest.-Nine P.M.: The cough was almost incessant for an hour, from six to seven, (evening;) and since the visit this morning, she has spat up fully half a pint of pus, the greater portion of which came away so hastily, that it might more justly be termed vomiting, than an act of ordinary expectoration. The upper part of the fluid in the spittoon-that last excreted-is frothy, bronchial mucus; the remainder, which constitutes the principal bulk, is pure pus, of a greenish-yellow colour, very consistent, and similar to the contents of an ordinary abscess which has been slow in forming. Increased nourishment; wine and beer ad libitum.

13th--Very little cough since last night, has rested well, and is cheerful and composed to-day; skin warm, inclined to gentle perspiration; expectoration rather less than on the 11 th, the day preceding the rupture of the vomica, but puriform; tongue not so much coated, glazed and shining.-Nine P.M. : Has had little cough and expectoration during the day, but is much depressed in spirits, in consequence of the bowels having acted four times since tea; the evacuations were costire, attended with much tenesmus; expectoration scanty, not exceeding one ounce, more bronchial in composition than puriform. Castor oil directly.

14th.-Slept well; expectoration copious again, and mixed with plenty of pus. Much the same, in other respects.

15th.-Much improved to-day, having passed another good night; cough only occasional; expectoration copious and puriform; tongue clean; takes plenty of nourishment.

17th.-Visit her now only once daily; cough at intervals, but not distressing; breathing free; expectoration copious, more bronchial in character; pulse regular; bow els open once daily; the only complaint she makes is of the accession of sudden and cold perspirations.

18th.-Cough has been rather troublesome during the night, at intervals; there is not more than half the quantity of sputa, which is generally more bronchial than heretofore.

19 th - Did not sleep well during the night; complains of the cough, but much more of the perspirations, which occur on the slightest movement, and occasion much distress; pulse weak and depressed; there is a tendency, moreover, to diarrhœa, the bowels having acted three times spontaneously. Plenty of bottled stout. 